\title{
2014 EASO Position Statement on the Use of Anti-Obesity Drugs
}

\author{
Hermann Toplak ${ }^{a}$ Euan Woodward ${ }^{b}$ Volkan Yumuk ${ }^{c}$ \\ Jean-Michel Oppert ${ }^{d}$ Jason C.G. Halford ${ }^{e}$ Gema Frühbeck ${ }^{f}$ \\ ${ }^{a}$ Department of Internal Medicine, Medical University, Graz, Austria; ${ }^{b}$ European Association \\ for the Study of Obesity, London, UK; ' ${ }^{c}$ Division of Endocrinology, Metabolism and Diabetes, \\ Istanbul University Cerrahpasa Medical Faculty, Istanbul, Turkey; ${ }^{d}$ Department of Nutrition, \\ Pitie-Salpetriere Hospital (AP-HP); Institute of Cardiometabolism and Nutrition (ICAN),

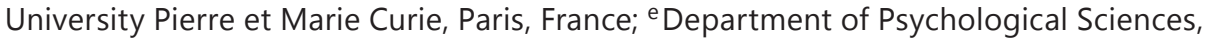

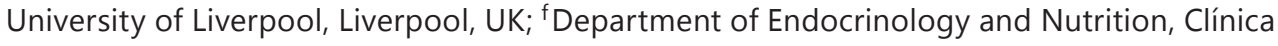 \\ Universidad de Navarra, University of Navarra, Obesity \& Adipobiology Group of the \\ Instituto de Investigación Sanitaria de Navarra, CIBERobn, Instituto de Salud Carlos III, \\ Pamplona, Spain
}

The European Association for the Study of Obesity (EASO) considers obesity to be a health, research, and societal priority [1]. It promotes the study of obesity. Moreover, the EASO facilitates and engages in actions that reduce the burden of unhealthy excess weight in Europe through prevention as well as management and prevent and combat the epidemic of obesity.

Although overweight and obesity are considered the 5th leading risk for death globally according to the WHO [2], clear opportunities for diagnosis and, consequently, treatment are being missed [3]. The EASO recently published a position statement in which the significance of obesity was re-defined as a rising public health, clinical, and scientific challenge in Europe. Obesity is a 'gateway' for many other diseases, such as dyslipidemia, hypertension, diabetes, and vascular disease [1]. Obesity should therefore be seen as one of the main targets for current efforts to combat the increasing non-communicable disease (NCD) epidemic [4]. Consequently, redefined obesity treatment strategies were also published [5]. In line with EASO's commitment to improve and guarantee an appropriate, comprehensive treatment quality for obese patients, criteria for EASO collaborating centers on obesity management (EASO-COMs) have been published [6], and the network has successfully been rolled out and is rapidly growing throughout more than 30 countries in Europe.

For the treatment of obesity and its co-morbidities, effective weight loss and subsequent weight maintenance are of particular importance. With a mean weight loss effect below 5\%, simple lifestyle approaches alone do not help the majority of cases reach treatment targets. The only reimbursed medical alternative today is bariatric surgery which is (according to European guidelines) indicated for type 2 diabetics with obesity grade II 
Toplak et al.: 2014 EASO Position Statement on the Use of Anti-Obesity Drugs

and for all obesity grade III patients. Bariatric surgery allows for a clinically significant mean weight loss above $15 \%$ of initial body weight. There is an important gap in the treatment options to achieve weight loss of up to $15 \%$ in obesity grade I subjects and overweight patients with co-morbidities. Lifestyle intervention in combination with drugs could fulfill this role. In Europe we lack therapeutic options available elsewhere, particularly the USA. There are a number of new drugs registered in the USA which are included in recently published US guidelines [7].

\section{Role of Weight Management in Patient Therapy}

In brief, weight management is not only important in itself but regarded as essential in the management of concomitant diseases. While the long-term goal of obesity management is to reduce morbidity and mortality, there are numerous short-term benefits. Obesity management leads to marked improvements in blood glucose control, hypertension, dyslipidemia, and other co-morbidities like osteoarthritis as well as to a reduction in the risk (and severity) of obstructive sleep apnea. As excessive weight plays also an important role in the development of cancer, gout and depression, treatment of obesity could be beneficial or at least preventive in their further deterioration [8]. Successful weight loss has also been shown to improve quality of life, mobility, daily function, and psychological well-being; pharmacotherapy may potentiate these effects. Many of these drugs are purported to operate by strengthening endogenous energy regulation systems and moderating appetite sensations. These have the potential to help the obese gain better control over their eating behavior, and limit their energy intake, making weight management easier. Given the negative psychological consequences of dieting (cravings, obsession with food, dysphoria, and cognitive impairment) and the physiological effects of energy restriction (reductions in endogenous GLP-1 and leptin associated with hunger), such pharmaceutical approaches might have profound effects on patients' experience of weight management.

\section{Targets of Weight Management in Overweight and Obesity}

Obesity is a complex condition of multifactorial origin with key internal and external drivers. This multifactorial origin not only explains the rise in prevalence across distinct populations but also individual variation within these. Biological susceptibility combined with psychological and social/situational factors promote weight gain, and deleterious outcomes are associated with adiposity. Obesity management should no longer focus solely on body weight (and BMI) reduction [9]. Given the role of body composition in obesity-related ill health; attention should be paid to a reduction of waist circumference or waist-to-hip ratio (especially in females) and the improvement in body composition (measured with body composition tracking systems like air-displacement plethysmography, dual energy X-ray absorptiometry, or bioelectrical impedance analysis), with a main focus on ameliorating or maintaining fat-free mass and decreasing fat mass $[1,2]$. In some patients, especially in those who are overweight (BMI $25.0-29.9 \mathrm{~kg} / \mathrm{m}^{2}$ ), but also in older patients, prevention of further weight gain (through dietary advice and increase in physical activity) rather than weight loss per se may be an appropriate target. Weight loss objectives should always be realistic, individualized, and aimed at the long term. A practical weight loss objective of 5-10\% over a period of 6 months is realistic and has a proven health benefit $[1,2]$. A greater weight loss may be considered for those with greater degrees of obesity (BMI $\geq 35 \mathrm{~kg} / \mathrm{m}^{2}$, obesity grade II and III). 
Toplak et al.: 2014 EASO Position Statement on the Use of Anti-Obesity Drugs

Maintenance of weight loss as well as prevention of new and treatment of current co-morbidities constitute the three main criteria for success. Obesity is a chronic disease for which follow-up and continued supervision is necessary lifelong in order to monitor disease risks, treat co-morbidities (e.g., type 2 diabetes mellitus, cardiovascular disease), and prevent weight regain [10].

\section{The Present Status of Anti-Obesity Treatments}

Treatment should be individually tailored, and clinical care providers should be able to provide a wide spectrum of clinically proven treatment options and combinations of them, for example:

- Individual or group lifestyle modification

- Lifestyle modification including dietary supplements (such as very low calorie diets

(VLCDs))

- Addition of anti-obesity drugs

- Addition of bariatric surgery.

Lifestyle intervention is the basis for the treatment of overweight and obesity, whenever possible. When performed by trained and specialized personnel, such treatment has improved considerably, at least in patients who are 'manageable'. This improvement is due to the development of transdisciplinary approaches, including dietary, exercise and behavior modifications, while also considering psychosocial characteristics of patients.

Pharmacological treatment should only be considered as part of a comprehensive strategy of disease management [11]. However, as an adjunct pharmacotherapy can help patients to maintain compliance, ameliorate obesity-related health risks, and also improve their quality of life [12]. By supporting body weight reduction, these drugs also appear beneficial in preventing the development of obesity-related co-morbidities (e.g. type 2 diabetes mellitus). Drugs should be used according to their licensed indications and restrictions. Currently, drug therapy is recommended for patients with a BMI $\geq 30 \mathrm{~kg} / \mathrm{m}^{2}$ or a BMI $\geq 27 \mathrm{~kg} / \mathrm{m}^{2}$ with an obesity-related co-morbidity (e.g. hypertension, type 2 diabetes mellitus). The efficacy of pharmacotherapy should be evaluated after the first 3 months of therapy (responders). If weight loss is considered satisfactory ( $>5 \%$ weight loss in patients without and $>3 \%$ in patients with diabetes), treatment should be continued. Improvements in waist circumference and/or body composition could also be used as alternative, more realistic, indicators for success. Treatment should be discontinued in non-responders, or - if possible - an alternative therapy should be used [5].

Currently, the options for obesity pharmacotherapy worldwide vary. In Europe, the only available approved drug for weight management is orlistat. This triglyceride lipase inhibitor reduces fat absorption by $30 \%$. Given that its site of action is within the gastrointestinal tract, its expected gastrointestinal side effects may have behavioral consequences in terms of the avoidance of energy-dense high-fat foods [13]. Orlistat is available in two dosages: $120 \mathrm{mg}$ t.i.d. (prescription) and $60 \mathrm{mg}$ t.i.d. (OTC). In combination with a hypocaloric low-fat diet it is adding a mean effect of 3-4\% supplementary weight loss to the lifestyle intervention [14] which may appear modest, but in responder subgroups such effect might be higher. The published data demonstrate efficacy and safety over a period of 4 years [15]. Importantly, orlistat has a beneficial effect on blood pressure, LDL-cholesterol, and insulin resistance resulting in improvements of blood glucose. This effect contributes significantly to the prevention of type 2 diabetes $[11,16,17]$.

While bariatric metabolic surgery is a far more effective intervention in terms of weight loss (15-40\% weight loss of initial body weight), it is invasive and may not be appropriate for 
Toplak et al.: 2014 EASO Position Statement on the Use of Anti-Obesity Drugs

the majority of patients; moreover its widespread use may be limited due to the high number of patients. Thus there is a significant need for more effective noninvasive treatment options bridging the gap between lifestyle modifications plus orlistat and surgical interventions. A number of new drugs for weight management are currently being tested in clinical trials worldwide [18]. Such medications could serve as new treatment options. In future, a polytherapeutic strategy may possibly rival surgery concerning efficacy, safety, and achievements of weight loss [19].

\section{Medical Treatment for Obesity - Regulatory Update}

With this unsatisfactory situation in mind, in 2012 the US Food and Drug Administration (FDA) registered two new drugs (lorcaserine and an extended-release topiramate/phentermine combination) [20] and, recently (September 2014), a third one, namely a combination of naltrexone and bupropion.

Lorcaserin (10 mg b.i.d.) is a selective serotonin $5-\mathrm{HT}_{2 \mathrm{C}}$ agonist that regulates food intake and results in approximately $3-4 \%$ of body weight loss [21]. The drug is the latest in a long line of 5-HT-based approaches to control appetite. 5- $\mathrm{HT}_{2 \mathrm{C}}$ agonism, along with 5-HT release and re-uptake inhibition, has been shown to suppress hunger and strengthen satiety. Despite historical issues of safety with regard to serotoninergic drugs, at present the safety profile of lorcaserin is regarded to be acceptable, at least where it is licensed. Thus, the drug may be an interesting treatment option, especially in 12-week responders revealing good weight loss of approximately $10 \mathrm{~kg}$ after 1 year [22]. However, the drug has not been approved in Europe. It is the opinion of the Committee for Medicinal Products for Human Use (CHMP) that, based on the current evidence, the benefits of the drug did not outweigh its risks.

The second drug is an extended-release combination of two well-known drugs topiramate and phentermine, using 23/46 and $92 \mathrm{mg}$ of topiramate and 3.75/7.5 and $15 \mathrm{mg}$ of phentermine. This drug combination is designed to suppress appetite and enhance satiety although clinical data demonstrating an appetite reduction of these drugs, either individually or in combination, is lacking. Indeed, the modes of action of topiramate on energy intake are still poorly understood. However, this novel drug combination is efficacious, showing a weight reduction of approximately $10 \%$, and is regarded as a safe treatment option [23]. Recently it has been demonstrated that this combination is also able to prevent diabetes in a pre-diabetic population [24, 25]. However, this drug combination has not been approved in Europe. In 2012 and 2013 the CHMP voted against the approval of this topiramate/phentermine combination on the basis 'that the long-term safety of this combination, particularly in the cardiovascular and psychiatric areas, had not been completely defined.' It should be noted that the development program for these agents included a 2-year study, met the size and duration requirements set by the EMA; moreover, these drugs are not unknown quantities as the single agents have been on the market around the world and used by millions of patients for more than 15 years for a variety of indications. However, although given at lower doses, any combination of known CNS-acting drugs could produce synergistic effects and discrete psychological phenomenona that may not be detected by standard adverse events reporting. Nonetheless, using standing approved monitoring methods the safety profile of topiramate/phentermine in its development program did not reveal anything new as compared to the existing approved monotherapy product labels. On the other hand, the weight loss and other benefits of treatment, including reduction in blood pressure and improvements in other important cardiovascular and metabolic biomarkers, were well demonstrated [20]. Further monitoring of the cardiovascular events of the combined therapy (post-marketing surveillance on new trails) should in time address these concerns. In the light of the withdrawal of rimonabant, 
Toplak et al.: 2014 EASO Position Statement on the Use of Anti-Obesity Drugs

the CHMP concerns may be taken in account that EMA requirements should be revised for all centrally acting agents to improve the detection of rare and serious psychiatric events. Well validated psychometric tools and experimental tests exist for such a purpose.

The third drug available in the USA is again a combination. Naltrexone is an opioid antagonist for the treatment of opioid and alcohol dependency, whereas bupropion is a norepinephrine/dopamine re-uptake inhibitor used to treat depression and smoking cessation. Opioid antagonists have been demonstrated to decrease hunger and specifically the palatability of preferred foods (using tasty sweet and /or high fat foods associated with high energy density). The effects of bupropion on human appetite have yet to be adequately characterized although its effects on appetite could be mediated by dopaminergic reward mechanisms. Naltrexone 8-32 mg and bupropion 90-360 mg in combination (NB32), although ineffective as individual monotherapies for obesity, produce weight loss and a metabolic profile beneficial for the potential treatment of obesity. According to current data [26], the efficacy of this combination seems slightly less than that of topiramate/phentermine but superior to orlistat and lorcaserin. It has to be stated that there is a FDA warning label addressing rare and but severe psychiatric side effects which must be acknowledged. With regard to approval in the EU, the CHMP has raised many additional questions that the company had to answer [27]. Specifically, the CHMP requested further justification of the balance of benefits and risks of NB32 treatment as well as additional information regarding post-approval risk minimization measures and pharmacovigilance activities. Finally the CHMP has voted for the drug combination in December 2014, and we look forward to the final decision by the European Parliament.

Another promising drug for obesity treatment is the GLP-1 agonist liraglutide. GLP-1 infusions produce reliable reductions in energy intake through decreases in pre-meal hunger and the strengthening of post-meal satiety which are effects sometimes seen with GLP-1 analogues and agonists [28]. This GLP-1 agonist has been extensively studied in type 2 diabetes and is marketed as a treatment of it in many countries worldwide. Some patients do exhibit side effects, mainly nausea at the beginning of the therapy (which clearly may lead to discontinuation in that phase). Nonetheless, the safety profile of the drug over the long term appears excellent. As obesity and diabetes are so inter-linked as disorders, widening the indication for liraglutide use to obesity in pre- or non-diabetic populations may be reasonable [29, 30]. In a study using liraglutide $3 \mathrm{mg}$ once daily for obesity treatment, a weight loss of approximately $6 \%$ was achieved, with even better performance when applied after a VLCD [31].

In the USA, liraglutide (0.6-1.8 mg) is available for diabetes treatment since 2010. An FDA advisory panel has voted 14 to 1 in favor of liraglutide for the treatment of obesity resulting in a subsequent approval by the FDA. The drug is also under consideration within the European regulatory process.

A recent review of all these pharmaceutical agents stated that all potentially available drugs could facilitate weight reduction as treatments [32]. However, their most important clinical contribution could be the prevention of weight regain after effective non-pharmacologically induced weight loss [33]. This approach could include sustaining the effects of other interventions such as VLCD together with lifestyle management or more focused behavioral support. These comprehensive approaches have the potential to produce large and longlasting benefits for the patient. However, the current regulatory environment focusses on weight loss rather than weight regain prevention.

\section{Outcome Studies}

Cardiovascular (CV) outcome studies are currently not required for approval of obesity drugs. However, in the past and present CV outcomes seem to attract particular attention also in obesity drugs. In a population that in any case is at great risk of CV outcomes, drug effects 
that could potentiate this risk clearly pose a problem. It is important to note that recent clinical trials on obesity drugs, designed within the current regulatory frame of short- to medium-term use lasting up to 2 years, have not revealed any safety concerns with regard to either topiramate/phentermine or lorcaserin. Guidelines formulated by the EASO with the aim to facilitate the decision making regarding the use of obesity drugs of course should be based on clinical evidence. Therefore, appropriately designed CV safety studies should be conducted for new obesity agents pre or post approval. Only in those drugs with no effect on validated markers of CV risk or a mechanistic rationale making CV effects extremely unlikely (e.g., orlistat that acts within the gastrointestinal tract and is not absorbed), an additional CV safety study seems to be dispensable pre or post approval.

CV outcome studies are costly in terms of time. So, in order to allow for an fast access to new therapies for patients in need, an approval decision should take into consideration if a drug showed clear and beneficial effects on validated surrogates of $\mathrm{CV}$ risk in phase II or phase III trials. The relationship between surrogate risk and endpoint outcome is not simple, especially if the trial does not model actual clinical practice both in prescribing and continuation. For example, sibutramine, which today is no longer licensed for clinical use, showed to elevate blood pressure in the pre-approval phase. This surrogate finding was eventually confirmed by increased incidence of hard CV endpoints in the SCOUT trial. However, the SCOUT trial itself included of a high number of patients with at least one contra-indication for sibutramine at baseline, a population the drug was not intended for [34]. Interestingly, it has recently been found that rapid weight loss and marked blood pressure reduction in the beginning of the SCOUT trial increased CV events in patients with cardiovascular disease [35]. It should also be noted, unlike in clinical practice, that patients not exhibiting weight loss (non-responders) remained in the study. This is important as a recent detailed analysis of the SCOUT study demonstrated that, while the sibutramine group experienced more primary outcome events than the placebo group, greater weight loss reduced overall risk of these occurring in both groups [36].

The regulatory balance is of course difficult to strike. CV problems have caused considerable concern in the past, and this has persuaded regulators to look critically at a number of new agents. Beyond the clear imperative of safety, potential CV risks of drugs must be addressed in order to make sure that patients have confidence in the treatment and consequently benefit from pharmacotherapy. However, a potential requirement for demonstration of long-term CV safety before approval for all obesity drugs not only clearly restricts availability of new agents for obese patients but also stifle further advances in the obesity field which may lead to next-generation therapeutics. The FDA is currently following cardiologic expert advice and is asking for appropriate post-approval outcome studies [37, 38]. This, in conjunction with the effective use of validated surrogates pre approval, should reduce the likelihood of adverse $\mathrm{CV}$ outcomes and allow potentially effective treatments to reach patients far sooner. In Europe, the mandatory requirement for pre-approval CV outcome studies is highly problematic considering that only few effective treatments for obesity are available. This does not mean that CV outcome studies generally should not be done but that high-risk populations where the drugs in any case would be contra-indicated should be excluded in order to reflect clinical use of a drug also in the pre-approval risk assessment.

\section{Next Steps}

In Europe, we are currently facing a situation in which high prevalence rates of overweight and obesity collide with a scenario in which effective pharmaceutical treatments are unavailable. The time has come to initiate regular discussions regarding the cardiometabolic 
Toplak et al.: 2014 EASO Position Statement on the Use of Anti-Obesity Drugs

risks of pharmaceutical obesity therapy with key stakeholders and decision makers throughout Europe at the EU and country level. Through this we may gain both a wider understanding of the extent of the obesity epidemic and a deeper appreciation of urgent unmet medical needs in the management of obesity. Clearly this discussion must be evidence-based. The riskbenefit ratio within the European context is of paramount importance. But risks that cannot be assessed within existing clinical trials as the patient groups included do reflect a selected target population for such a drug therapy should not be a prerequisite for drug approval. Even though they must be addressed in additional appropriate studies, a post-clinical assessment seems to be sufficient and justified.

The EASO therefore calls on the European Commission, the European Parliament, the CHMP, and all member states to work together to ensure that new obesity treatment options can be more readily available in order to eliminate the extensive unmet medical needs in this area to the benefit of European citizens and society. This does not mean that we abandon the risk-benefit model but that we plead for adapting it systematically and effectively to the approval and regulatory process. A platform of measures and tools already exists than can be deployed pre and post approval to assess risk in intended populations. If we are successful in managing obesity, we will block a key progression route of many major chronic diseases. A progress in the treatment of obesity would be a major social and economic achievement and of personal significance for the millions of obese individuals and their families seeking help.

\section{Acknowledgements}

The authors would like to acknowledge the contribution of Dr Emma Boyland, Department of Psychological Sciences, University of Liverpool, Liverpool, UK.

\section{Disclosure Statement}

HT has served as an advisor for Vivus and Novo Nordisk. JCGH declares his involvement as a member of a U.K. Novo Nordisk Advisory Board. GF has participated in a Novo Nordisk Obesity Scientific Communication Global Advisory Board Meeting.

\section{References}

1 Frühbeck G, Toplak H, Woodward E, Yumuk V, Maislos M, Oppert JM: Obesity: the gateway to ill health - an EASO position statement on a rising public health, clinical and scientific challenge in Europe. Obes Facts 2013; 6:117-120.

2 World Health Organisation: Fact Sheet No.311 (May 2012). www.who.int./mediacentre/factsheets/fs311/en/.

3 Frühbeck G: Obesity: screening for the evident in obesity. Nat Rev Endocrinol 2012:8:570-572.

4 Beaglehole R, Bonita R, Horton R, Adams C, Alleyne G, Asaria P, Baugh V, Bekedam H, Billo N, Casswell S, Cecchini M, Colagiuri S, Collins T, Ebrahim S, Engelgau M, Galea G, Gaziano T, Geneau R, Haines A, Hospedales J, Jha P, Keeling A, Leeder S, Lincoln P, McKee M, Mackay J, Magnusson R, Moodie R, Mwatsama M, Nishtar S, Norrving B, Patterson D, Piot P, Ralston J, Rani M, Reddy KS, Sassi F, Sheron N, Stuckler D, Suh I, Torode J, Varghese C, Watt J; Lancet NCD Action Group; NCD Alliance: Priority actions for the non-communicable disease crisis. Lancet 2011;377:1438-1447.

-5 Yumuk V, Frühbeck G, Oppert JM, Woodward E, Toplak H, for the Executive Committee of the European Association for the Study of Obesity: An EASO position statement on multidisciplinary obesity management in adults. Obes Facts 2014;7:96-101.

6 Tsigos C, Hainer V, Basdevant A, Finer N, Mathus-Vliegen E, Micic D, Maislos M, Roman G, Schutz Y, Toplak H, Yumuk V, Zahorska-Markiewicz B: Criteria for EASO-collaborating centres for obesity management. Obes Facts 2011;4:329-333. 
Toplak et al.: 2014 EASO Position Statement on the Use of Anti-Obesity Drugs

7 Garvey WT, Garber AJ, Mechanick JI, Bray GA, Dagogo-Jack S, Einhorn D, Grunberger G, Handelsman Y, Hennekens CH, Hurley DL, McGill J, Palumbo P, Umpierrez G, On Behalf Of The Aace Obesity Scientific Committee: American Association of Clinical Endocrinologists and American College of Endocrinology consensus conference on obesity: building an evidence base for comprehensive action. Endocr Pract 2014;20: 956-976.

8 Maggio AB, Martin XE, Saunders Gasser C, Gal-Duding C, Beghetti M, Farpour-Lambert NJ, Chamay-Weber C: Medical and non-medical complications among children and adolescents with excessive body weight. BMC Pediatr 2014;14:232.

-9 Blundell JE, Dulloo AG, Salvador J, Frühbeck G, on behalf of the EASO SAB Working Group on BMI: Beyond BMI - phenotyping the obesities. Obes Facts 2014;7:322-328.

10 Tsigos C, Hainer V, Basdevant A, Finer N, Fried M, Mathus-Vliegen E, Micic D, Maislos M, Roman G, Schutz Y,Toplak H, Zahorska-Markiewicz B: Management of obesity in adults: European clinical practice guidelines. Obes Facts 2008;1:106-116.

11 Hainer V, Toplak H, Mitrakou A: Treatment modalities of obesity: what fits whom? Diabetes Care 2008; 31(suppl 2):S269-S277.

12 Patrick DL, Skalicky AM, Edwards TC, Kuniyuki A, Morales LS, Leng M, Kirschenbaum DS: Weight loss and changes in generic and weight-specific quality of life in obese adolescents. Qual Life Res 2011;20:961-968.

13 Toplak H, Marhardt K: Reduction of obesity and improvement in metabolic parameters by inhibition of intestinal lipases: current results with orlistat. Acta Med Austriaca 1998;25:142-145.

14 Van Gaal LF, Broom JI, Enzi G, Toplak H: Efficacy and tolerability of orlistat in the treatment of obesity: a 6-month dose-ranging study. Orlistat Dose-Ranging Study Group. Eur J Clin Pharmacol 1998;54:125-132.

15 Torgerson JS, Hauptman J, Boldrin MN, Sjöström L: XENical in the prevention of diabetes in obese subjects (XENDOS) study: a randomized study of orlistat as an adjunct to lifestyle changes for the prevention of type 2 diabetes in obese patients. Diabetes Care 2004;27:155-161.

16 Sharma AM, Golay A: Effect of orlistat-induced weight loss on blood pressure and heart rate in obese patients with hypertension. J Hypertens 2002;20:1873-1878.

-17 Hutton B, Fergusson D: Changes in body weight and serum lipid profile in obese patients treated with orlistat in addition to a hypocaloric diet: a systematic review of randomized clinical trials. Am J Clin Nutr 2004;80: 1461-1468.

18 George M, Rajaram M, Shanmugam E: New and emerging drug molecules against obesity. J Cardiovasc Pharmacol Ther 2014;19:65-76.

19 Rodgers RJ, Tschop MH, Wilding JP: Anti-obesity drugs: past, present and future. Dis Model Mech 2012;5: 621-626.

20 Colman E, Golden J, Roberts M, Egan A, Weaver J, Rosebraugh C: The FDA's assessment of two drugs for chronic weight management. N Engl J Med 2012;367:1577-1579.

-21 Yanovski SZ, Yanovski JA: Long-term drug treatment for obesity: a systematic and clinical review. JAMA 2014; 311:74-86.

-22 Smith SR, O'Neil PM, Astrup A, Finer N, Sanchez-Kam M, Fraher K, Fain R, Shanahan WR: Early weight loss while on lorcaserin, diet and exercise as a predictor of week 52 weight-loss outcomes. Obesity (Silver Spring) 2014;22:2137-2146.

23 Sweeting AN, Tabet E, Caterson ID, Markovic TP: Management of obesity and cardiometabolic risk - role of phentermine/extended release topiramate. Diabetes Metab Syndr Obes 2014;7:35-44.

24 Garvey WT: Phentermine and topiramate extended-release: a new treatment for obesity and its role in a complications-centric approach to obesity medical management. Expert Opin Drug Saf 2013;12:741-756.

25 Garvey WT, Ryan DH, Henry R, Bohannon NJ, Toplak H, Schwiers M, Troupin B, Day WW: Prevention of type 2 diabetes in subjects with prediabetes and metabolic syndrome treated with phentermine and topiramate extended release. Diabetes Care 2014;37:912-921.

26 Verpeut JL, Bello NT: Drug safety evaluation of naltrexone/bupropion for the treatment of obesity. Expert Opin Drug Saf 2014;13:831-841.

27 www.biotechnologyevents.com/node/7809.

28 Torekov SS, Madsbad S, Holst JJ. Obesity - an indication for GLP-1 treatment? Obesity pathophysiology and GLP-1 treatment potential. Obes Rev 2011;12:593-601.

-29 Iepsen EW, Torekov SS, Holst JJ: Therapies for inter-relating diabetes and obesity - GLP-1 and obesity. Expert Opin Pharmacother 2014;15:2487-2500.

30 Ng SY, Wilding JP: Liraglutide in the treatment of obesity. Expert Opin Biol Ther 2014;14:1215-1224.

-31 Wadden TA, Hollander P, Klein S, Niswender K, Woo V, Hale PM, Aronne L: Weight maintenance and additional weight loss with liraglutide after low-calorie-diet-induced weight loss: the SCALE Maintenance randomized study. Int J Obes (Lond) 2013;37:1443-1451.

32 Bray GA: Medical treatment of obesity: the past, the present and the future. Best Pract Res Clin Gastroenterol 2014;28:665-684.

33 Manning S, Pucci A, Finer N: Pharmacotherapy for obesity: novel agents and paradigms. Ther Adv Chronic Dis 2014;5:135-148.

-34 Caterson I, Coutinho W, Finer N, Van Gaal L, Maggioni A, Torp-Pedersen C, Sharma AM, Ge H, Santoro D, Shepherd G, James P; SCOUT Investigators: Early response to sibutramine in patients not meeting current label criteria: preliminary analysis of SCOUT lead-in period. Obesity (Silver Spring) 2010;18:987-994. 
Toplak et al.: 2014 EASO Position Statement on the Use of Anti-Obesity Drugs

-35 Seimon RV, Espinoza D, Ivers L, Gebski V, Finer N, Legler UF, Sharma AM, James WP, Coutinho W, Caterson ID: Changes in body weight and blood pressure: paradoxical outcome events in overweight and obese subjects with cardiovascular disease. Int J Obes (Lond) 2014;38:1165-1171.

-36 Caterson ID, Finer N, Coutinho W, Van Gaal LF, Maggioni AP, Torp-Pedersen C, Sharma AM, Legler UF, Shepherd GM, Rode RA, Perdok RJ, Renz CL, James WP; SCOUT Investigators: Maintained intentional weight loss reduces cardiovascular outcomes: results from the Sibutramine Cardiovascular OUTcomes (SCOUT) trial. Diabetes Obes Metab 2012;14:523-530.

37 Fleming JW, McClendon KS, Riche DM: New obesity agents: lorcaserin and phentermine/topiramate. Ann Pharmacother 2013;47:1007-1016.

38 Cunningham JW, Wiviott SD: Modern obesity pharmacotherapy: weighing cardiovascular risk and benefit. Clin Cardiol 2014;37:693-699. 